\title{
11. BASIC PRACTICE METHODS IN UNIVERSITY GENERAL PIANO CLASSES
}

Cristina Andra Raducanu ${ }^{99}$

\begin{abstract}
The purpose of this article was to present and analyse some practicing piano methods which are used during secondary piano lessons at the university. The final goal was to show the benefits of these practice strategies in the process of learning a new piano piece. Experience demonstrated that in order to keep students motivated, there is a need for them to know how to approach and study a new repertoire and to be sure that implementing these practice methods will help them gain the necessary skills which will enable them to fluently perform a musical piece.
\end{abstract}

Key words: piano pedagogy, piano practice techniques, secondary piano, new repertoire, memorize

\section{Introduction}

My experience of over 15 years as a pianist as well as a piano teacher allowed me plenty of time to observe and think about the most important ways of practicing this instrument in order to accomplish the best results in the shortest amount of time. The lessons and interaction with my students, regardless of how old or how advanced in piano playing they were led me to the conclusion that most problems they had in solving technical issues represented the natural outcome of lacking certain skills and not knowing how to practice particular passages.

The ultimate goal in performing a musical piece is to understand the composer's intentions and to be able to bring the expressive message of the piece into the light. In other words, playing the piano is not about strictly playing all the right notes, about being able to accurately execute a certain piece of music, but about the way you do it. It is really a question of HOW you play it. But in order to be able to materialize one`s musical and creative intentions, one needs to have the technical means and to know how, when and where to make use of them in order to achieve that musical goal. So having a good piano technique at one's disposal is of most importance in the success or failure of becoming a good pianist.

\section{Approaching a new piano piece}

There are some methods of practicing which make the proper learning of a new piano piece much easier. Although it is important to know how you want to play a certain piece of music, to get to the point where you have made up your mind about your way of understanding and interpreting a certain musical piece, this is not enough if you do not know how to get to that point. It is of great importance to learn how to correctly approach the study of a musical piece in order to learn it better, faster and to develop and improve your technical

\footnotetext{
99 Lecturer PhD., "George Enescu" National University of Arts from Iaşi, Romania, email:
} cristina@rraducanu.ro 
possibilities at the same time. From the first contact with a new musical piece, the student has to decode the musical text. The student's mission is to get to know the piece and to understand its structure. At this point he/she will make some interconnections between this new piece and the repertoire addressed during the piano classes until that point in time. It will always be helpful if the new piece belongs to a composer or a certain stylistic period already known by the interpreter, because this way, it will be easier for him/her to understand it and to obtain a general point of view regarding the way of interpreting it.

Understanding a new piano work written by an unfamiliar composer will take longer, because the student does not have any material for comparison. In this case he will come to a conclusion regarding the interpretation during the process of decoding its structure, practicing the piece technically and expressively until he/she reaches a valid and justified perspective. For example, especially in teaching secondary piano, the first period, when the student is effectively learning the piece, is of most importance for the future performance, because this is the time which represents the basis of the future sound construction.

The methods used to "conquer" the piece represent the key to future success or failure. Different ways of practicing which are apparently very simple and sometimes underrated open the way to a conscious and very focused learning process which leads to astonishing good results with secondary piano students. Due to the fact that these students have only one piano lesson per week, most of them do not own an instrument, so it is a real challenge to find time for exercising among all other classes and other responsibilities they may have, and perhaps most important of all, they do not see these classes as very important to them (even if they are wrong), because they are focusing more on their main subjects. Consequently, my goal in the classroom is to make the hour they spend with me and the piano most attractive. This means that I try to instill the pleasure of playing by showing them that they can be good at it without practicing as much as they would have expected.

\section{Practicing methods used in teaching secondary piano}

First of all, I use the method of playing the new piano piece separately. This approach of reading a score with one hand at a time is naturally easier than with both hands together and it helps them better understand what happens on an horizontal level. This method of practice is highly recommended for them, because it helps them achieve independence in each hand. It is also very useful in polyphonic pieces (e.g. little preludes, two and three part inventions, fugues by Bach), where each hand must be able to sustain an individual melodic line. Playing separately at first also simplifies the process of choosing the right fingering and writing it down on the music sheet. Insisting on the right fingering is one of the most important things with secondary piano students, because many of them have issues with this subject. Since piano has never been their main instrument, a lot of them did not pay the right amount of attention to the aspect of correct fingering in the years before university and they come with 
major problems in this area, because they have not acquired any previous piano skills or they have wrong habits, which is worse. The best way to convince them to use the proper fingering is to explain the logic behind it and to demonstrate it on the piano.

Second of all, I always try to make them determine for themselves which fragments are the most difficult, to "extract" them from the musical piece and to try to solve the occurring technical problems. In order to do so, I try to explain to them which factors are causing the problem. This is the starting point to finding a solution. After dividing the problem into its components, I show them how they have to practice in order to solve it. Most of the time, we are doing it in the classroom, so they have a model of practice to follow at home. The motivation for them to follow my instructions while studying alone is given by the fact that they immediately may see a progress in their playing. My advice to them is to practice the most challenging parts separately, then to play small sections which include them and then, if they can do that correctly and with ease, they can play the whole piece. The division of the piece in small parts and studying them individually is recommended for separate or both hands together.

Concentrating on smaller sections helps to learn better and faster. This way of practicing, alternating smaller parts with the whole piece, will lead to the successful mechanical performance of the piece. "It is a process of automatisation of the smallest elements of the action of playing and thus of modelling various complex skills. They represent, from a physiological point of view, dynamic stereotypes that are reinforced into systems." ${ }^{100}$ Through rehearsing again and again and a continuous pursuit of development, abilities will become fully acquired. However, being able to perfectly play a small part gives the student already a feeling of accomplishment and satisfaction and the belief that he will be able to master the whole piece in the end, by putting all the parts together like a puzzle. However, playing the piece time after time with little or no sign of improvement gives them a feeling of failure and frustration which does not encourage them to continue practicing, because they sense that the final goal is too hard to reach.

After using the methods of practicing the most difficult areas until solved, dividing the piece in logical fragments and practicing them separately, students will come to the point where they will be able to play separately the whole work. Here comes the moment when they will have to begin exercising with both hands together. The easiest and fastest way to succeed in learning the whole piece is to make use once again of the methods explained above (practicing most difficult passages, exercising small and bigger sections and then the whole work). The process of memorizing is also of great importance, since the students are required to play a musical piece from memory at the end exam.

\footnotetext{
${ }^{100}$ Mircea Dan Raducanu, (2017), Principii de didactica instrumentala, Editura Artes, Iasi
} 


\section{Some advice regarding memorization techniques}

Depending on the pianistic level of the students and on the difficulty grade of the work in study, the memorization takes place before, during the period of technically exercising the piece or afterwards. My observation was that, for example, the method of memorizing one hand at a time (for example in difficult sections, which the student seems not to be able to tackle) helps beginners play easier with both hands together. Naturally, it is recommended to firstly choose to learn the notes from whatever hand has the easier part.

This way, playing them together, the student is more likely to be capable of focusing on the notes of the more difficult hand while playing the first one by heart. In order to be sure that they are playing the melody from one hand by heart, I use to cover the already memorized hand with a piece of paper and so I encourage them to focus on the reading of the melody of the other hand. When they succeed in doing that without any mistakes, I take the piece of paper away and let them play from the score. Most of them are very happy to observe that by using this method they can play simultaneously without studying very much. In order to memorize the piece, my advice for them is to begin with small sections. These are the most comfortable for the brain to comprehend and process. At first these pieces will enter the short-term memory, then, through practicing, they will be part of the long-term memory and finally the student will have that section learned for good.

Studying in this way, there will be less chances for the student to forget the notes during the final exam. That is the reason why I always emphasize the importance of aiming for perfection during the process of memorizing small sections at a time through a longer period of time. From my experience, students who hope to learn a whole piece just before the exam aren't able to perform it flawlessly, because the piece is only anchored in their short-term memory and this is not enough, especially when having to play under stressful conditions like an exam.

\section{Other practice strategies}

During the complex process of learning a new piano piece, besides alternating exercising with separate or both hands, exercising certain technical difficult passages, alternating section study with whole piece study, it is of great importance to know that there are ways of studying a piece of music which are not written in the text. A good knowledge and awareness of these and of course, implementing these methods in one's daily studying routine help the students be more efficient and economic with their time and also get better results in their performance. It is known that "good psycho-motor control enables students to play more expressively from the very first stages of practicing each piece". ${ }^{101}$ Among these strategies we can count playing staccato, playing dynamically different (this means forte or piano), playing forte with a heightened emphasis

\footnotetext{
${ }^{101}$ Robert Pace, (2000), Keyboard technique and effective psycho-motor skills, in The essentials of keyboard pedagogy, Lee Roberts Music Publications, Inc., 8
} 
on the articulation of the fingers, using the metronom to play from a slow to a fast tempo and count out loudly every beat or even the subdivisions of it (eighth notes, sixteenth notes) if there are some rhythmical difficulties or strongly accentuating the strong beats in order to get the right metrical feeling. It is recommended to vary these practice techniques, because this way the student will be able to pay attention for a longer period of time and his memory will also be strengthened. It is also important to repeat one method until there is an improvement or, even better, until the student can do it (almost) perfectly and then practice using another method.

After the piece was learned properly and memorized, a good strategy for students would be to record themselves. Another way of preparing for playing in public is to visualize the act of playing. This is a mental way of practicing without touching the piano keys, but it requires a lot of thinking and concentration power, so I would recommend it to more advanced students. This method clearly improves memory and helps students who suffer from performance anxiety. Thinking ahead about the event to come and truly visualizing the whole act of playing before the exam/public performance help them go through the experience more times before the real one and if they succeed mentally, the chances to succeed in real life exponentially increase.

All these methods are used directly on the repertoire to be learned, which per semester means one etude and one piano piece from a certain stylistic period. In an idealistic environment, with more than one piano class per week and with students having the possibilities of practicing at home, it is not only recommended, but a must to combine practicing separately specific technical issues (like scales, double notes, chords, arpeggios, etc.) with practicing the ongoing repertoire. In the short period of time remaining in the classroom, most of the time it is impossible to practice different types of technical exercises at the beginning of the class, so I just try to choose their repertoire in so that I cover different aspects of techniques which we then try to master during the lessons. Otherwise, "not only different types of exercises strengthen the necessary muscles and improve the speed of fingers, but they develop the skill of performing technical formulae that are frequently met in the pianistic literature. The gain of these basic skills of the pianistic language will considerably ease the work of the pianist on the artistic repertoire". ${ }^{102}$

\section{Conclusions}

I deliberately emphasized the role of practicing methods in this article referring almost only to how to study in order to able to fluently play a given piece. This does not mean that during the secondary piano classes we do not pay any attention to artistic and expressive playing. The latter is the primary aim in all piano playing. "Naive mechanists of the early- nineteenth century viewed the primary task of piano pedagogy as imparting pianistic technique; therefore, they explicitly demanded that artistic music be banned from piano lessons, until

\footnotetext{
${ }^{102}$ Mircea Dan Raducanu, (2007), Studii de psihopedagogie pianistica, Editura Pim, Iasi
} 
children acquired a sufficient level of technique”. ${ }^{103}$ But today's piano pedagogy acknowledgments require that the student's attention must be guided towards a musical goal.

So the above presented methods are always connected with the musicalinterpretive issues which occur in the given musical text. We cannot separate the technical problems from the interpretive ones, because solving the first represents just a means of being able to gain the necessary skills to play any given piece as a work of art, with an expressive meaning.

Anyway, this kind of learning a new musical piece by using different practicing methods teaches the students the necessary skills to work on their own and helps them feel that they have accomplished something, which can be a good motivation to continue practicing.

\section{Bibliography}

1. Mircea Dan Raducanu, (2017), Principii de didactica instrumentala, Editura Artes, Iasi

2. Robert Pace, (2000), Keyboard technique and effective psycho-motor skills, in The essentials of keyboard pedagogy, Lee Roberts Music Publications, Inc., p. 8

3. Mircea Dan Raducanu, (2007), Studii de psihopedagogie pianistica, Editura Pim, Iasi

4. Lia Laor, (2016), "In music nothing is worse than playing wrong notes" : Nineteenth - century mechanistic paradigm of piano pedagogy, in Journal of Historical Research in Music Education, Vol. 38(I) 5-24, 11

\footnotetext{
${ }^{103}$ Lia Laor, (2016), “In music nothing is worse than playing wrong notes” : Nineteenth - century mechanistic paradigm of piano pedagogy, in Journal of Historical Research in Music Education, Vol. 38(I) 5-24, 11.
} 